\title{
De historiadores y de los posibles usos de su saber: la contribución de los Congresos Internacionales de Historia de América en la conformación de una identidad americana (décadas de 1930 a 1960)
}

\author{
Historians and the possible uses of their knowledge: The contribution \\ of the International Congresses of the History of America in the \\ conformation of an American identity (decades of 1930-1960)
}

\section{Martha Rodriguez}

\section{RESUMO}

El objetivo de este artículo es reflexionar sobre los sentidos e interpretaciones del pasado construidas y enunciadas desde el campo historiográfico, pero cuyo impacto trasciende las fronteras del mundo académico para reverberar en otros ámbitos. Un objeto privilegiado para aproximarse a esas dimensiones historiográficas son los congresos y reuniones científicas, especialmente aquellos donde la dimensión cognitiva, científica o pedagógica del saber se conjuga con la intervención pública, la política o la diplomacia. Analizaremos los Congresos Internacionales de Historia de América celebrados en Buenos Aires entre las décadas de 1930 y 1960. En ellos, los historiadores, apoyados en la legitimidad de su saber, diseñaron intervenciones en las que la historia ocupó un lugar central, contribuyendo, con argumentos y motivos historiográficos, a establecer algunos sentidos sobre la identidad americana, sobre el pasado y el futuro del continente y sobre su papel en el concierto internacional.

\section{PALAVRAS-CHAVE}

Historiografía; Historia de América; Congresos científicos.

\section{ABSTRACT}

The objective of this article is to reflect on the meanings and interpretations of the past built and enunciated in the historiographical field, but whose impact transcends the boundaries of the academic world to reverberate in other spaces. Congresses and scientific meetings are privileged means to approach these historiographical dimensions, especially those where the cognitive, scientific and pedagogical dimension of knowledge are conjugated with public intervention, politics or diplomacy. We will analyze the International Congresses of the History of America held in Buenos Aires between the decades of 1930-1960. In these congresses, historians, supported by the legitimacy of their knowledge, designed interventions in which history had a central place, contributing with historiographical arguments and reasons to establish some meanings about the American identity, about the past and the future of the continent and about its role in the international context.

\section{KEYWORDS}

Historiography; History of America; Scientific congresses. 


\section{Los congresos cientificos como objeto de estudio}

En las últimas décadas, la historia de la historiografía ha asistido a una dilatación de su campo temático, superando las limitaciones contenidas en el énfasis por las constelaciones de ideas de los cultores de la historia. Reivindica como objetos territorios más vastos: las diferentes formas de gestión del conocimiento histórico, los modos de construcción y circulación de los relatos históricos, los complejos vínculos entre la historiografía profesional y otras construcciones sobre el pasado y sus usos públicos.

Este artículo se inscribe en esos desplazamientos, pues nos proponemos reflexionar desde una perspectiva historiográfica sobre los vínculos entre la actividad académica y profesional de los historiadores y el mundo extrahistoriográfico. Nos detendremos en particular sobre sentidos, interpretaciones e imágenes del pasado construidas y enunciadas desde el campo historiográfico, pero cuyo impacto trasciende las fronteras del mundo académico para reverberar en otros ámbitos.

Durante buena parte del siglo $X X$ fueron habituales los eventos donde la producción y circulación de conocimiento histórico construido por reconocidos profesionales de la disciplina fueron más allá de la dimensión cognitiva o pedagógica. Congresos y reuniones académicas desbordaron en varias ocasiones los ámbitos en los que fueron diseñados y la estricta función científica para impactar en la opinión pública, la política nacional o la diplomacia internacional. ${ }^{1}$

Desde las últimas décadas del siglo XIX, los congresos adquirieron una centralidad hasta entonces desconocida en el mundo científico. Alentados por el proceso de profesionalización disciplinar que estaba teniendo lugar en los distintos campos del saber - y al que contribuirían en forma directa - , en su seno se desplegaron simultáneamente las variadas aristas del campo científico: tanto el debate colectivo, la investigación y los avances científicos, como las disputas por el reconocimiento, la consagración y el poder e, incluso, la voluntad de exhibir ante
1 - Citamos aquí sólo dos ejemplos referidos al ámbito americano. En el III Congreso Científico Panamericano, realizado en Lima en 1924, el historiador argentino Ricardo Levene presentó un proyecto para la redacción de un manual de historia americana destinado a la enseñanza media. Aprobado en la sesión plenaria, se creó una comisión de cinco historiadores encargados de la redacción de la obra en el plazo de tres años para su uso en las escuelas de todos los países americanos. Aunque el proyecto nunca se concretó plenamente, su sola propuesta refuerza la hipótesis planteada. En el I Congreso de Historia Nacional y en la VII Conferencia Internacional Americana, organizados en Montevideo en 1928 y 1933, respectivamente, los historiadores participantes recomendaron a los Estados americanos estrechar las relaciones por medio de tratados que contemplaran la revisión de los libros de texto de historia y geografía. Algunos se materializaron en la década siguiente, como se verá más adelante. 
los poderes públicos - y ante la opinión pública en general - lo producido puertas adentro de la academia. Pensados generalmente con una lógica ecuménica - como la ciencia misma - la escala internacional reforzó la idea de un campo científico reunido en torno de un mismo propósito que excedía - y minimizaba - la adscripción nacional de sus integrantes. Aunque limitaciones y restricciones formales e informales operen en la práctica para poner en cuestión ese ecumenismo, tensionado entre intereses - y rivalidades - nacionales y el ideal de una ciencia universal, tal como lo demuestran varios de los estudios sobre los Congresos Internacionales de Historia (BLÄNSDORF 2010; HÜBINGER; PICHT; DABROWSKA 2010; ERDMANNT 2005), es innegable que constituyeron una de las expresiones de la internacionalización del campo científico desde fines del siglo XIX (GINGRAS 2002).

Hasta hace un par de décadas, las investigaciones históricas repararon en los congresos científicos fundamentalmente por la información que ofrecen sobre las áreas del saber a las que se aplican y los aportes científicos que estimulan. Sin embargo, en los últimos años se profundizó y amplio el interés por ese objeto no solo cuantitativamente, sino atendiendo al valor que encierran en sí mismos como instancias de formalización a partir de las cuales aprehender formas y mecanismos de la vida intelectual, de los campos profesionales y de las disciplinas académicas (PROCHASSON 1989).

En tanto organizaciones dotadas de continuidad institucional, expresada generalmente en un órgano permanente con estatus jurídico, autoridades y regularidad en sus ediciones, los congresos científicos, tomados como objeto de estudio, permiten analizar cuestiones tan variadas como prácticas sociales, redes científicas nacionales e internacionales, vectores de transferencia de saberes o la importancia relativa de cada comunidad científica nacional en las distintas áreas del conocimiento (FEUERHAHN; RABAULT-FEUERHAHN 2010). ${ }^{2}$

Ha sido largamente estudiado el rol de los historiadores y de la historia en la construcción de tradiciones identitarias en los
2 - Según señalan Feuerhahn y Rabault-Feuerhahn (2010), las investigaciones desde esas nuevas perspectivas fueron prácticamente inexistentes hasta la última década del siglo $X X$ y relativamente poco exploradas hasta hace unos 10 años. Entre las existentes, pueden citarse los trabajos reunidos en: "Les congrès lieux de l'échange intellectuel 1850-1914", Mil Neuf Cent, 1989; "Les congrès scientifiques internationaux", en Relations internationales sur, 1990; "La fabrique internationale de la science", Revue Germanique internationale, 2010. También hay algunas obras dedicadas al estudio de congresos con centralidad en los campos disciplinares. Para el campo historiográfico, los Congresos Internacionales de Historia, organizados por el Comité Internacional de Ciencias Históricas, y los Congresos Internacionales de Americanistas concitaron alguna atención (LÓPEZ-OCÓN 2002; ERDMANNT 2005; LAURIERE 2010). 
orígenes de los Estados nacionales. Y la forma en que, en ese contexto, la historia se convirtió en una disciplina profesional, en un saber científico al que se le adjudicó capacidad para reconstruir con objetividad el pasado. Los Estados nacionales apoyaron y se valieron del estatus alcanzado por la historia, demandándole a sus cultores colaboración en la tarea de nacionalización de las masas y, más tarde, en la de fortalecer otros sentimientos de pertenencia 0 bien determinados valores. Esas demandas estatales y la dimensión bifronte científica y pedagógica - que los historiadores le asignaron a su profesión, contribuyeron a potenciar el prestigio social y el impacto extracadémico de la ciencia histórica. En ese sentido, los congresos de historia se destacan entre sus pares de otros campos por su riqueza y valor para el análisis de los vínculos entre el mundo académico y otros ámbitos.

En este artículo nos concentraremos en el análisis de tres ediciones de los Congresos Internacionales de Historia de América celebrados en Argentina: el Segundo Congreso Internacional de Historia de América (el primero organizado en la Argentina), planificado como parte de los actos oficiales por el IV Centenario de la primera fundación de Buenos Aires en 1937 (aunque la conmemoración fue en 1936, las actividades conmemorativas se extendieron más allá de ese año); el Tercer Congreso, desarrollado como parte de la conmemoración del sesquicentenario de la Revolución de Mayo en 1960; y el Cuarto, organizado como parte de los festejos por el sesquicentenario de la independencia en $1966 .{ }^{3}$

En ellos, los historiadores, apoyados en la legitimidad de su saber, diseñaron intervenciones en las que la historia ocupó un lugar central. $Y$ aunque los sentidos conferidos al pasado no los imponen solamente - y ni siquiera centralmente - los historiadores, esa gestión de la historia contribuyó con argumentos y motivos historiográficos a establecer algunos principios sobre la identidad americana, sobre el pasado y el futuro del continente y sobre su papel en el concierto internacional. En ese marco se desplegó un conjunto de
3 - En total, se realizaron seis ediciones: una en Brasil, una en Perú y cuatro en Buenos Aires. En artículos anteriores hemos reflexionado sobre los vínculos entre este tipo de eventos, las conmemoraciones $y$ la historiografía, a la vez que desarrollamos un análisis pormenorizado de cada uno de los congresos (RODRIGUEZ 2016; 2017; 2018). Para un estudio de los vínculos entre conmemoraciones, política $y$ diplomacia, ver ORTEMBERG (2014). 
propuestas que dieron pie al debate sobre los usos que la historia podía tener para dichos fines.

Atentos a esos objetivos, y aun a riesgo de opacar matices, priorizaremos aquí la reflexión de conjunto y las comparaciones por sobre el estudio exhaustivo de cada uno de los tres congresos. Aunque exploraremos las distintas coyunturas y los desplazamientos de sentido entre uno y otro, especialmente en lo referido a la identidad americana, privilegiaremos una aproximación general por sobre las diferencias.

\section{Políticas culturales de cooperación internacional entre la primera posguerra y la guerra fría}

Hacia fines de la década de 1910 comenzó a emerger un horizonte caracterizado por nuevas sensibilidades en el mundo cultural e intelectual americano. El fin de la Primera Guerra Mundial generalizó ciertas imágenes asociadas al suicidio de la civilización o al fin del progreso y, especialmente, a la decadencia de la vieja Europa, conmovida en sus cimientos por la guerra. Frente a ese panorama, América emergía, por contraste, como un continente joven, repleto de promesas de futuro. El fracaso europeo de la Gran Guerra abría para algunos intelectuales la oportunidad para América de asumir un liderazgo civilizatorio ante el mundo, presentado en variantes que pasaban por el latinoamericanismo, hispanoamericanismo, indoamericanismo o panamericanismo.

En ese contexto, desde los años 1920, Estados Unidos desplegaba su política de "buena vecindad" dirigida a reestablecer los vínculos con los países del continente. Trataba con ese cambio de disminuir la animosidad generada por su política exterior de intervención en la región y su afán de liderazgo continental. Esta política suponía defender los intereses norteamericanos por medios más sutiles que los empleados hasta el momento y estimular, al mismo tiempo, un panamericanismo que descansaba en la idea de una comunidad 
de intereses compartidos y un pasado común. ${ }^{4}$

También en las primeras décadas del siglo XX, en algunos sectores intelectuales y políticos españoles había ido cobrando forma una propuesta "regeneracionista" destinada a recuperar el sentido nacional y el prestigio internacional perdido a partir de la revalorización de los lazos tejidos con los territorios americanos a lo largo de los cuatro siglos de vínculo colonial. Sus ejes eran el rescate de la comunidad cultural de origen, el valor del idioma común, la reivindicación de la civilización latina frente a la anglosajona y la recuperación de la obra realizada por España durante la colonia, lo que implicaba rectificar la leyenda negra (DEL ARENAL 1994; PEREZ HERRERO; TABANERA 1993; PRADO 2010).

Lo cierto es que, al amparo de las reflexiones abiertas por la Primera Guerra Mundial, pero también por aquellas estimuladas por el ascenso de los fascismos, la exaltación desmesurada del nacionalismo y la rivalidad entre naciones, comenzaron a ser objeto de atención creciente en el mundo intelectual, en el diseño de políticas públicas y en las relaciones internacionales las investigaciones sobre la creación y difusión de esas ideas y sobre cómo contrarrestarlas. El despliegue de políticas culturales de cooperación y tolerancia destinadas a diluir rivalidades entre naciones se materializó, por ejemplo, en la creación de comisiones nacionales para estudiar los contenidos transmitidos por la escuela o en la firma de acuerdos bilaterales o conjuntos de trabajo sobre esos tópicos. Este movimiento también es perceptible en la importancia concedida por algunos gobiernos a las recomendaciones de congresos y conferencias internacionales. La construcción de esa diplomacia cultural se desplegó a partir de la década de 1920 con particular intensidad. ${ }^{5}$

A instancias de Argentina, se firmó en 1933 un convenio con la República de Brasil que disponía la revisión periódica de los textos de Historia y Geografía utilizados en el sistema educativo. El mecanismo para materializar ese acuerdo fue la creación de comisiones revisoras de la enseñanza de la Historia
4 - Esta política no bastó para superar las reticencias latinoamericanas hacia Estados Unidos. Aunque la "buena vecindad" y el ascenso de los fascismos disminuyeron la animosidad, desde mediados de los años 1920, el antiyanquismo fue una dimensión visible en algunos sectores de la cultura latinoamericana (BERGEL 2011). Con el tiempo, sin embargo, tanto los gobiernos latinoamericanos como amplios sectores de esas sociedades se fueron involucrando en intercambios cada vez más profundos con EEUU, sobre todo a partir de mediados de la década de 1930 (PERNET 2007). Sobre la constitución de un temprano latinoamericanismo culturalista en el contexto de la emergencia de los EEUU como una potencia hegemónica, puede consultarse SCARFI; PREUSS (2013); PITA GONZALEZ; MARICHAL (2012) y el clásico trabajo de NINKOVI$\mathrm{CH}$ (1981).

5 - Para un análisis de las relaciones político-culturales entre Europa y América Latina en este período, ver PERNET (2007); $y$, entre EEUU y América Latina, PITA GONZALEZ (2017). 
y de la Geografía americanas en ambos países. ${ }^{6}$

Las tareas desarrolladas por la comisión argentina en sus dos primeros años de existencia y la aceptación de sus propuestas en el seno del gobierno nacional estimularon a sus miembros a emprender tareas más ambiciosas. En julio de 1936, su presidente, el historiador Ricardo Levene, le propuso al ministro de Relaciones Exteriores aprovechar la Conferencia Interamericana de Consolidación de la Paz, que se realizaría unos meses más tarde en Buenos Aires, para organizar una reunión de delegados de los Ministerios de Instrucción Pública de los países americanos. ${ }^{7}$ El temario propuesto giraba alrededor del establecimiento de acuerdos para realizar una revisión de libros de texto de Historia y Geografía en toda América y para difundir las obras de autores americanos por medio de las escuelas (LEVENE 1942).

En la sesión de clausura de la Conferencia, el delegado de Venezuela, el Dr. Zèrega Fombona, propuso que se incluyera en actas la recomendación a los gobiernos de América de designar a la brevedad representantes para el II Congreso Internacional de Historia de América, que se realizaría en Buenos Aires al año siguiente. Sostenía que varias de las resoluciones votadas en esa conferencia tenían su base material, técnica y moral en dicho congreso y que, por lo tanto, su buen funcionamiento haría más visibles los proyectos de la Conferencia.

Esas y otras iniciativas de similar tenor confirman la firme política de intervención de los historiadores argentinos en eventos internacionales - especialmente los vinculados al mundo americano - y la importancia que tuvo esa participación en algunos aspectos de la política exterior. Esa diplomacia cultural descansaba sobre la convicción de la importancia de estimular la conciencia histórica.

En el ámbito local, el papel desempeñado por los historiadores en la esfera internacional y en instancias político-diplomáticas fue posible gracias a la consolidación del proceso de profesionalización y al entramado de un sistema de 
relaciones académicas, personales e institucionales controladas por historiadores de la denominada Nueva Escuela Histórica (DEVOTO; PAGANO 2009; CATTARUZZA; EUJANIAN 2003). Sus miembros habían logrado, para la década de 1930, el control de buena parte de las instituciones y empresas historiográficas y compartían una serie de premisas sobre la historia. En primer lugar, consideraban que la historia era una ciencia que, practicada según un canon metodológico riguroso, podía producir un relato objetivo - y por lo tanto verdadero - sobre el pasado. En segundo lugar, que la investigación histórica tenía un costado científico pero también uno pedagógico, cuyas virtudes cívicas y patrióticas hacían imprescindible la intervención de los historiadores en todas aquellas instancias e instituciones vinculadas a la construcción y difusión de una conciencia histórica.

El II Congreso Internacional de Historia de América y, luego, sus siguientes ediciones a lo largo del siglo XX constituyeron uno de los ámbitos en los que se desplegó con visibilidad y amplitud lo que denominamos embajada historiográfica, gestada por historiadores argentinos, pero compartida ampliamente por el conjunto de los representantes americanos.

A diferencia de la situación descrita, el contexto políticocultural en el que se desarrollaron el III y IV Congreso Internacional de Historia de América fue completamente diferente al de 1937. Desde mediados de siglo XX, la situación política se había transformado profundamente en Argentina, en América y en el mundo. El huracán de la modernización y la radicalización del cambio avanzaban en Occidente, expandiéndose a universos variados. El clima mundial enfatizaba el pasaje a la acción y la violencia política como el recurso posible - cuando no la ultima ratio - para la transformación social. El éxito de la Revolución cubana en 1959 mostraba que esas opciones no eran solo utopías para América. La salida revolucionaria, más allá de sus formas concretas, ganaba adeptos pero también generaba reacciones a gran escala (TERAN 2008). En el contexto del enfrentamiento ideológico característico de la guerra fría, la creación de la Alianza para el Progreso, la difusión de la doctrina de la seguridad nacional 
y el creciente predominio de las fuerzas armadas en Latinoamérica convergían como respuestas ante ese escenario inquietante.

Esa tensión creciente estimuló también el trabajo de nóveles organismos internacionales, centros académicos y fundaciones en pos de investigaciones, instrumentos y materiales que permitieran avanzar en la creación de consensos y en la colaboración entre naciones, aunque esos se pensaran desde la retícula intelectual provista por el mundo occidental. En ese marco, el interés por el estudio de los sistemas educativos y todas aquellas instituciones vinculadas a la construcción de una cultura histórica y cívica cobraron un nuevo impulso. La UNESCO, la OEA, la OEI, el Consejo de Europa fueron promotores importantes de esas investigaciones $y$, bajo su influencia, fueron retomadas por gobiernos, universidades y academias (UNESCO 1950).

La Argentina también transitaba en esos años por un convulsionado escenario político. El golpe de Estado contra el gobierno de Juan Perón, producido en 1955, había profundizado el creciente predominio de las fuerzas armadas y sellado la proscripción del peronismo, dos elementos que condicionarían los procesos políticos y sociales de los años siguientes. A mediados de la década siguiente, el desprestigio del sistema de partidos, la inestabilidad política, el avance de concepciones que sustituían la política por administración y legitimaban la intervención militar con el argumento del peligro que enfrentaban los valores occidentales y cristianos, decantaron en un generalizado apoyo a propuestas de modernización autoritaria del país. ${ }^{8}$

\section{Los Congresos İnternacionales de Historia de América}

Los Congresos Internacionales de Historia de América estuvieron, desde sus inicios, asociados a actos conmemorativos. El primero de la serie se había celebrado en Río de Janeiro en septiembre de 1922 con motivo del centenario de la Emancipación de Brasil (PASCHOAL GUIMARÃES 2005). Su organización había quedado en manos del Instituto Histórico
8 - El gobierno emanado de la Revolución argentina en 1966 procedió a la intervención de las universidades nacionales para limpiarlas "de toda ideología marxista". El hecho más difundido de esa política, la "Noche de los Bastones Largos", abrió un proceso de renuncia en masa -especialmente significativo en la Universidad de Buenos Aires-de una parte importante de los planteles de docentes e investigadores, afectando particularmente a aquellos vinculados a las experiencias de renovación y modernización del campo científico y cultural abiertas en 1955 y que habían tenido notable impacto en las ciencias sociales. 
y Geográfico Brasileño, una de las primeras instituciones latinoamericanas dedicadas al estudio del pasado nacional a partir de una labor erudita y heurística. Atento a los lazos que unían esa institución a la Junta de Historia y Numismática Americana y a los historiadores argentinos en pleno proceso de profesionalización, su comisión organizadora invitó al historiador argentino R. Levene a incorporarse al evento en calidad de vicepresidente.

A instancia suya, en las sesiones plenarias se decidió que el congreso funcionase con carácter permanente y se designó a Buenos Aires como anfitriona-organizadora del siguiente. La fecha prevista era el 25 de mayo de 1923. Sin embargo, problemas de diversa índole conspiraron contra la realización en esa fecha. Quince años más tarde la coyuntura era bien diferente. A la consolidación del campo profesional y al ascenso de sus figuras centrales a posiciones expectables, se sumaba la afinidad de la Junta de Historia y Numismática Americana con los gobiernos conservadores, especialmente la del presidente de la institución, R. Levene, con el presidente de la Nación, el General Agustín P. Justo. Por eso, no fue sorprendente que un congreso de historia fuera uno de los eventos centrales entre los organizados para conmemorar el IV centenario de la primera fundación de la ciudad de Buenos Aires.

El II Congreso Internacional de Historia de América se gestó, así, como iniciativa de la Junta de Historia y Numismática Americana, elevada al año siguiente al rango de Academia Nacional de la Historia (ANH), pero con el carácter poliédrico que le confería su condición simultánea de reunión científica, acto conmemorativo y gestión diplomática. Esta impronta marcará el desarrollo de dicho congreso y de las siguientes ediciones, que oscilarán intermitentemente entre historiografía, conmemoración y política.

El presidente Justo emitió un decreto, el 14 de enero de 1937, que oficializaba el II Congreso sobre la base de su trascendencia como acto conmemorativo, empresa cultural e historiográfica y estímulo para la consolidación de la solidaridad continental. 
Esa normativa establecía la convocatoria, por intermedio del Ministerio de Relaciones Exteriores, a las universidades y academias de historia de todos los Estados americanos y España e invitaba a las escuelas dependientes del Ministerio de Justicia e Instrucción Pública a designar profesores de historia para participar de la sección "Metodología de la enseñanza de la historia americana y revisión de textos". La comisión organizadora del congreso fue presidida por Levene, mientras que las vicepresidencias quedaron a cargo de reconocidos historiadores de todo el continente. ${ }^{9}$

La convocatoria tuvo gran acogida en el país y en toda América a juzgar por la amplitud de instituciones que respondieron a la invitación. Buena parte de los gobiernos provinciales, universidades y academias nacionales, filiales provinciales de la Junta de Historia y Numismática Americana, archivos, bibliotecas y museos provinciales y nacionales, la Comisión Nacional de Cooperación Intelectual y la Escuela Superior de Guerra enviaron representantes. A ellos se sumaron los representantes oficiales y de universidades de Estados Unidos, México, Guatemala, El Salvador, Colombia, Venezuela, República Dominicana, Cuba, Nicaragua, Costa Rica, Panamá, Brasil, Ecuador, Perú, Bolivia, Paraguay, Chile, Uruguay y España.

El evento se desarrolló entre el 5 y el 14 de julio de 1937. En la apertura estuvieron presentes el presidente Justo, el ministro de Justicia e Instrucción Pública, Jorge de la Torre, el de Interior, Manuel Alvarado, el de Agricultura, Miguel A. Cárcano, el intendente municipal, M. de Vedia y Mitre, el cardenal primado, monseñor Copello, una cantidad importante de diputados y senadores, miembros del cuerpo diplomático argentino y embajadores de países americanos.

En el caso del III Congreso Internacional de Historia de América, la Comisión Nacional Ejecutiva de Homenaje al $150^{\circ}$ aniversario de la Revolución de Mayo promovió la iniciativa propuesta originalmente por Levene en 1958, poco antes de que falleciera, oficializando el evento como parte central de

\begin{abstract}
9 - Clarence Haring y Percy Alvin (EEUU), Alfonso Reyes y Toussaint (México), José Rodríguez (Venezuela), Max Fleiuss y Pedro Calmon (Brasil), Antonio Pons y José Navarro (Ecuador), Felipe Barreda Laos y Horacio Urteaga (Perú), Alcides Arguedas (Bolivia), Luis Barros Borgoño y Domingo Amunátegui Solar (Chile), Felipe Ferreiro y Mario Espalter (Uruguay), Rómulo Carbia y Emilio Ravignani (Argentina).
\end{abstract}


los festejos y sosteniéndolo económicamente. La convocatoria formal invitaba a archivos, museos, juntas de estudios históricos, bibliotecas nacionales y provinciales, comisiones nacionales con jurisdicción sobre museos y patrimonio, universidades, institutos de investigaciones históricas, revistas de historia, centros y círculos de las FFAA, así como a las áreas de cultura y educación de los gobiernos nacional y de la provincia de Buenos Aires. También se participó a instituciones americanas y españolas vinculadas al quehacer historiográfico, a las que se sumaba, como una novedad de esta edición, la invitación a otras de origen francés vinculadas a la investigación y la enseñanza de la historia americana.

Las sesiones del III Congreso se llevaron a cabo entre el 12 y el 17 de octubre de 1960. La inauguración se produjo con la presencia de autoridades del gobierno nacional y del poder ejecutivo y legislativo de la Municipalidad de la Ciudad de Buenos Aires, funcionarios de las áreas de cultura y educación, más de sesenta historiadores provenientes de Brasil, Colombia, Chile, Perú, Ecuador, España, EEUU, Francia, Haití, México, Paraguay, Perú, Uruguay, Venezuela y centenares de historiadores locales. Las autoridades nacionales intervinieron activamente mediante los discursos de Luis Mc Kay, ministro de Educación, en la inauguración, y de Alfredo Vitolo, ministro de Interior y presidente de la Comisión Nacional Ejecutiva de Homenaje al $150^{\circ}$ aniversario de la Revolución de Mayo, en la clausura.

El IV Congreso, que contó con el auspicio y el apoyo de la Comisión Nacional Ejecutiva del Sesquicentenario del Congreso de Tucumán y de la Declaración de la Independencia, sesionó entre el 5 y el 12 de octubre de 1966. Aunque entre los preparativos iniciales del evento y su concreción mediaron una serie de acontecimientos políticos imprevistos, ni el golpe de estado que derrocó a Arturo Illia ni la intervención a las universidades nacionales alteraron las actividades previstas por los organizadores. La inauguración se produjo con la presencia de autoridades del gobierno nacional - entre ellas, el general Onganía, a cargo de la presidencia luego del golpe,- y, como 
ya era habitual en estos congresos, con la participación de funcionarios de las áreas de cultura y educación, miembros de la $\mathrm{ANH}$, del resto de las academias nacionales, representantes de un conjunto de universidades, institutos de investigaciones históricas, archivos, museos, bibliotecas, revistas de historia e instituciones de las fuerzas armadas. A ellos se sumaban casi un centenar de historiadores vinculados a entidades dedicadas a los estudios americanistas de Alemania, Bolivia, Brasil, Canadá, Costa Rica, Colombia, Chile, República Dominicana, Ecuador, España, Estados Unidos, Francia, Inglaterra, México, Panamá, Paraguay, Perú, Puerto Rico, Suecia, Uruguay y Venezuela.

Es significativo el estímulo creciente a extender invitaciones y fomentar la participación de países no pertenecientes al mundo iberoamericano. Esto rompía con la tradición inaugurada en la I y II edición, que restringía - no formalmente, pero sí en la práctica, por medio de las invitaciones oficiales - la participación a ese universo. El cambio, perceptible ya en el III Congreso pero profundizado en el IV es, como veremos, atribuible en gran medida a las transformaciones mundiales operadas desde mediados del siglo XX, especialmente la consolidación de un mundo bipolar $y$, consecuentemente, el realineamiento de la historia americana $-y$, en particular, de la herencia hispánica - en la genealogía del mundo occidental.

Tanto en el congreso de 1937 como en los de 1960 y 1966, es sintomático el vínculo entre el sector hegemónico del campo historiográfico local, representado institucionalmente por la $\mathrm{ANH}$, y los poderes públicos, aunque el signo político de éstos últimos variara notablemente entre una y otra edición, incluyendo gobiernos democráticos y dictaduras. Los congresos contaron, en las actividades de apertura y cierre $-y$, en algunos casos, también en las sesiones -, con la presencia de altas autoridades del poder ejecutivo nacional, embajadores y funcionarios provinciales y locales. Varios de ellos intervinieron activamente con discursos y participaron en las actividades extraacadémicas. ${ }^{10}$ Más allá de afanes conmemorativos y de consensos interpretativos y pedagógicos, a ello sin duda

\begin{abstract}
10 - El programa de los congresos no sólo incluía actividades académicas: visitas culturales, banquetes $y$ reuniones sociales con autoridades $y$ excursiones turísticas se sucedían a lo largo de los días que duraba el evento - nunca menos de ocho -, contribuyendo a la sociabilidad de la comunidad internacional de historiadores.
\end{abstract}


contribuyó el que varios historiadores, a la vez conspicuas autoridades de la $\mathrm{ANH}$, integraran también las respectivas comisiones nacionales de homenaje o fueran funcionarios públicos. Casos como los de Carlos Pueyrredon y Ricardo Levene, en el II Congreso, o el de Roberto Etchepareborda y Ricardo Caillet Bois, en el III, son algunos ejemplos en ese sentido. ${ }^{11}$

Sin embargo, quizá lo más significativo de las continuidades encontradas entre las distintas ediciones del Congreso Internacional de Historia de América esté dado por el énfasis puesto en explotar los alcances de las reflexiones e investigaciones científicas más allá de los límites de la academia. Los congresos fueron pensados por sus organizadores y vistos por el mundo político y académico como espacios de convergencia de una multiplicidad de objetivos. A la reflexión histórica, el estímulo a las investigaciones originales sobre la historia americana y la sociabilidad académica que caracterizan cualquier congreso científico de este tenor, se le sumaba la faceta identitaria y diplomática, expresada en la defensa de la cooperación internacional y la solidaridad entre los Estados americanos.

La condición de posibilidad para la convergencia de esos objetivos descansaba en la convicción de que verdad histórica e interés nacional/regional podían conciliarse. $Y$ en la de que el ejercicio de la profesión tenía un costado científico y otro pedagógico y que, por lo tanto, la búsqueda de la "verdad histórica" era perfectamente compatible con el amor a la patria y éste, bien entendido, maridaba sin dificultades con ideales de factura americana. La pertenencia a un colectivo americano no competía con las identidades nacionales, sino que se apoyaba sobre ellas y su historia. Era el desconocimiento o, en todo caso, el mal conocimiento, el que fomentaba las rivalidades y recelos, y no las diferencias ideológicas, los proyectos políticos o las voluntades de liderazgo. La búsqueda de la objetividad conducía a un mismo tiempo al desarrollo de un trabajo científico y a la solidificación de una identidad nacional y americana. Investigación, docencia, patriotismo y espíritu americano se entramaban sin dificultad.
El caso de Roberto Etchepareborda es paradigmático de esta situación. Era miembro de la Comisión Nacional de Homenaje y de la $A N H$, pero, además, diplomático, ministro, concejal y presidente del Concejo Deliberante de la Ciudad de Buenos Aires y mantenía vínculos estrechos con políticos e intelectuales cercanos al presidente Arturo Frodizi. En 1960, su decidida labor garantizó el espacio del Concejo Deliberante para el Desarrollo del Congreso y la organización de una variedad de actividades culturales y sociales para los invitados. Aunque excede los objetivos de este trabajo, nos permitimos hipotetizar que ese vínculo entre los sectores más significativos del campo historiográfico $y$ el poder político y la consecuente intervención de los historiadores profesionales en el ámbito público, político o diplomático, es un fenómeno en franco retroceso a partir de la década de 1970, por lo menos en Argentina. Es probable que algunas de las causas estén vinculadas con las transformaciones operadas en el campo historiográfico a partir de la reapertura democrática en 1983, especialmente con la forma de concebir el trabajo del historia- 


\section{La identidad americana}

En lo que resta del artículo nos concentraremos en las características de esa identidad americana y en sus deslizamientos, reconfiguraciones y reelaboraciones historiográficas a lo largo de los tres congresos.

Durante la apertura del II Congreso en 1937, su presidente, el historiador R. Levene, destacaba con satisfacción la superación de una etapa en la que la historia del continente era escrita a partir de la tensión y el conflicto entre los países: "Era en parte la historia de la América inglesa contra la América latina o viceversa; la historia de la América hispánica contra la portuguesa y chocaban entre ellos la mayoría de los historiadores de pueblos de habla castellana [...]" (LEVENE 1938, p. 29).

La razón de esa transformación la relacionaba con el despliegue de una nueva concepción histórica, difundida gracias a la profesionalización disciplinar que se estaba llevando adelante en toda América. Apoyada en la aplicación de los métodos eruditos de investigación y crítica, permitía elaborar una historia de las unidades americanas en su diversidad y en su totalidad. Los procedimientos de investigación aseguraban alcanzar la verdad histórica y realizar una historia comprensiva y de síntesis. Al mismo tiempo, un nuevo compromiso pedagógico de los historiadores con la cultura histórica contribuía a su difusión.

Por sobre las diferencias geográficas, raciales, económicas y políticas, las investigaciones históricas demostraban para Levene la unidad histórica de carácter moral que distinguía al mundo americano. Esa historia compartida, que ligaba estrechamente a las naciones americanas, no hacía más que señalar cómo "Los Estados libres de este Continente marchan hacia la plena realización de su soberanía económica y espiritual y la historia es la unión entre ellos como fuente eterna de verdad y patriotismo" (LEVENE 1938, p. 35). dor y su vínculo con la sociedad y la política por parte de quienes detentaron posiciones hegemónicas en dicho campo a partir de ese momento. Esta situación parece estar revirtiéndose en los últimos años, pero por motivos diferentes a los analizados aquí. 
La idea de una unidad histórica y la consecuente y natural vocación americanista de los países del continente fue reforzada por otros oradores. El representante de Estados Unidos e invitado de honor, Clarence Haring, afirmaba que

La América española y la América inglesa son ambas el producto de la frontera. Ambas han estado condicionadas en el pasado de las circunstancias sociales y políticas que acompañan a la conquista material de un continente virgen; ambas encaran los mismos problemas políticos y sociales en el presente (HARING 1938, p. 41).

Más emotivo y explícito aún, el Dr. P. Calmon, representante de Brasil y también invitado de honor, iniciaba su interpelación al auditorio exclamando:

Es privilegio de nuestro continente este parentesco indisoluble [...] el sentido de su civilización es una profunda y natural solidaridad entre nuestros países, en cuyo sincronismo adivinamos el mismo drama social, igual aventura creadora, equivalente formación histórica. Somos, en este mundo nuevo, la humanidad nueva (CALMON 1938, p. 44).

Ese sustrato común a todo el continente daba un aval histórico a opciones políticas presentes:

La hora de la reconquista decisiva, de la América para los americanos, sonó en modo semejante. [...] De hecho nos comprendemos tan bien, que nunca un prócer americano, en la victoria o en la desgracia [...] se juzgó extranjero en país vecino. Los caballeros medioevales se hermanaban por la cruz; nosotros nos fraternizamos en la liberación" (CALMON 1938, p. 46).

La opción americanista - o panamericanista - se presentaba, así, más que como posibilidad, como destino ineluctable. El "monroismo no es, así, una novedad sino una verificación. Habíamos formado, más que nuestra espiritualidad, nuestro sistema. Éramos para los americanos forjados al calor de tantas turbulencias cívicas, la libre América" (CALMON 1938, p. 46).

Esa idea de que el espíritu de confraternidad americana 
estaba basada en la necesaria pero también inevitable unidad americana, sobrevoló todo el II Congreso. Las presentaciones y discursos enfatizaban aquellos elementos de la historia americana queacercabanalos Estados: su carácterdenacionesindependientes forjadas al calor de la disolución del vínculo colonial europeo y de las necesidades emanadas de los avatares de la construcción de nuevas naciones. En esa perspectiva, las identidades nacionales y la regional, lejos de generar tensiones y recelos, se afianzaban mutuamente. Del mismo modo, se minimizaban las divergencias entre las dos Américas, pues, a diferencia de otras opciones como el hispano o el latinoamericanismo, el americanismo compartido no excluía a nadie en el continente.

Sin embargo, eso no significó el rechazo a la herencia hispana de los países que la poseían, ni tampoco el debilitamiento de la centralidad concedida a la historia hispana e hispanoamericana tanto en las investigaciones como en la historia escolar. ${ }^{12}$ En ese contexto, el americanismo parece más bien el reforzamiento de una identidad de la que se destaca su común aspiración a la libertad frente a las derivas históricas de la situación europea, la que, en la coyuntura, permitía a los países que lo integraban posicionarse en el concierto internacional. En una inversión de esquemas, América y sus historiadores se convertían en faro para la cultura de la humanidad. Este americanismo se mantuvo en las siguientes ediciones del Congreso, aunque connotado de manera muy diferente.

Tanto en la tercera como en la cuarta edición del Congreso Internacional de Historia de América se acentuó el vínculo entre los temas del Congreso y el presente. En las convocatorias y los informes de las comisiones organizadoras se insistía en que, pese a tratarse de congresos vinculados al estudio y conmemoración de procesos históricos ocurridos a principio del siglo XIX, respondían también a preocupaciones y problemas actuales.

En 1960, Ricardo Zorroaquín Becú, secretario de la Comisión Organizadora del III Congreso y vicepresidente de la $\mathrm{ANH}$, sostenía que el tema central del congreso podía reducirse a "un solo asunto fundamental":
12 - Varias de las propuestas presentadas y aprobadas en el plenario general tendían a reforzar el legado colonial, especialmente el hispánico. Se pueden citar como ejemplos la creación de cátedras de Historia de la Civilización de España, Portugal e Inglaterra en las universidades de América donde no las hubiera; o aquella dirigida a los Ministerios de Educación para que dieran mayor importancia en sus programas a la historia de España. 
"Libertad e independencia en el nuevo mundo". No es por casualidad que se han elegido esas palabras. Ellas evocan sin duda todo el proceso emancipador pero traducen al mismo tiempo preocupaciones permanentes de nuestros países, que se agudizan en determinados momentos de nuestra historia. $Y$ es entonces con un doble sentido - pretérito y actual- que vamos a considerar ese asunto fundamental [...] (ZORROAQUÍN BECÚ 1961 , p. 86).

Seis años más tarde, Ernesto Fitte, presidente de la Comisión Organizadora del IV Congreso y secretario de la $\mathrm{ANH}$, argumentaba que:

El centro de gravedad del orbe se desplaza insensiblemente del viejo al nuevo continente y, dentro de poco, América Latina ha de tener a su cargo la rectoría moral del consorcio de las naciones libres que luchan por la dignificación humana. Este congreso tiene, pues, como principalísima misión a realizar, la de preparar el ambiente y adecuar las condiciones para este advenimiento (FITTE 1966, p. 111).

Tanto en las intervenciones del III como en las del IV Congreso abundaron las referencias a la situación internacional, al lugar de América en el concierto mundial y al rol que historia e historiadores debían desempeñar en los "arduos momentos contemporáneos", como los denominó más de un expositor. Para la mayoría de los participantes, aquellos estaban asociados al peligro del comunismo, expresado a escala latinoamericana por la entonces triunfante Revolución cubana y su potencial de ejemplaridad para estimular una cultura de la rebelión.

La historia era entendida en este contexto como un antídoto. La responsabilidad adjudicada a los historiadores era grande. El estudio erudito, serio y objetivo de la historia de los procesos emancipatorios americanos debía destacar las singularidades, pero, fundamentalmente, demostrar la indudable unidad americana, fraguada al calor de un pasado colonial común y, fundamentalmente, de una común experiencia de ruptura de ese vínculo.

En esas interpretaciones, si los avatares del proceso emancipatorio habían configurado las diferencias que 
caracterizaban a las distintas naciones $y$, al mismo tiempo, precipitado un conjunto de valores sustantivos a escala americana, era sin duda la matriz hispánica consolidada durante el período colonial y, con ella, la de la civilización occidental - de la que España formaba parte - la que había brindado la argamasa que hermanaba a las naciones americanas. Especialmente, el carácter espiritual y cultural de la conquista habría permitido la germinación de un conjunto de valores característicos del mundo occidental en el territorio americano. Esta herencia hispanooccidental ponía a los países americanos en inmejorables condiciones para atravesar y conducir un presente percibido como amenazador. Es de cara a esa nueva adscripción occidental del mundo americano que es leída, procesada y reivindicada la herencia hispánica del nuevo continente

La revalorización del hispanoamericanismo no era nueva en esos congresos. Había estado presente desde la segunda edición, aunque allí la impronta de la "América para los americanos" había teñido todo el evento. Pero, desde la década de 1960, tanto en el III como en el IV congreso, la exaltación del hispanismo pasó a ser más que la celebración de una comunidad cultural en el sentido romántico del término, convirtiéndose en una unidad espiritual ya no patrimonio exclusivo de Hispanoamérica, sino de todo el mundo occidental. La revalorización de España aparece así como parte de una interpretación metahistórica de la historia universal dentro de la que dicho país funcionaría como bisagra del mundo occidental, puente entre Europa y América. ${ }^{13}$

De "América para los americanos" se pasaba a "Hispanoamérica para el mundo" y los historiadores americanos estaban allí para presentar a Occidente la experiencia histórica del continente y la tradición en que se fundaban sus valores. Estaban llamados a cumplir una función formativa imprescindible, la de constructores de una coraza identitaria en la que lo nacional y lo americano se subsumían en lo occidental frente a la amenaza ideológica del comunismo. Su materialización se llevaría adelante por medio de sus investigaciones, del trabajo cotidiano en las aulas, de intervenciones públicas y publicaciones.

\begin{abstract}
13 - La filiación en una tradición hispánica espiritual y religiosa se expresa con particular intensidad en el IV Congreso y, especialmente, en los discursos de clausura del evento, donde esa recuperación es amplificada hasta convertirse en el núcleo que consolida a América como un bastión de defensa del mundo occidental.
\end{abstract}


El estudio de la historia latinoamericana, especialmente el de los procesos revolucionarios que condujeron a las independencias y, posteriormente, a la paulatina revinculación con las metrópolis, permitía realizar una operación historiográfica más; una en la que la historia funcionaría como prospectiva, convirtiéndose en prisma para conjeturar el futuro de procesos históricos con los que podían trazarse paralelismos pese a las diferencias espacio-temporales: las experiencias de descolonización y construcción de nuevas naciones iniciadas luego de la segunda posguerra.

Así lo expresaba el hispanista francés Raymond Ronze, ${ }^{14}$ quien, en su intervención en el III Congreso, señalaba su simpatía por la construcción de una cultura hispanoamericana que le permitía aventurar alguna posibilidad para la recreación de vínculos semejantes con las, en ese momento recientes, excolonias francesas: "La colonización francesa ha creado un África de expresión francesa, de la misma manera que España ha creado una América española" (RONZE 1961, p. 119). Sin embargo, y a diferencia de la dirección que habían tomado los vínculos entre América y España - de los que el mismo Congreso era una muestra y en cierto sentido una esperanza -, los de los países africanos con sus metrópolis estaban plagados de conflictividad y rechazo. Ronze creía encontrar la causa en

Esta doctrina de descolonización explotada por la potencia colonial más grande del mundo moderno: Rusia, que ha colonizado todo el Asia Central y Oriental durante el siglo XIX y a principios del siglo XX. La Unión Soviética conduce de nuevo en Europa el avance hacia el Oeste [...] Así explotada y transformada por la política soviética en teatro de la guerra fría llevada a cabo por Moscú contra los Estados Unidos y la Europa Occidental, la descolonización de África nos afecta profundamente sobre todo en Francia (RONZE 1961, p. 116).

A especulaciones similares estuvo dedicada en el IV Congreso buena parte de la exposición de otro invitado extranjero, el historiador Arnold Toynbee. En ella, el conocido autor de Estudio de la Historia señalaba que
14 - Los vínculos entre Ronze, el americanismo y la historiografía argentina eran de larga data (RONZE 1923). Para la construcción de un campo de estudios americanistas en Francia, puede consultarse LÓPEZ-OCÓN (2002) y HUERTA (2005).

La historia de Latinoamérica es de interés para los pueblos 
latinoamericanos, pero tiene también un interés general para toda la raza humana. La experiencia latinoamericana durante los últimos ciento cincuenta años nos proporciona cuanto puede ser un examen previo de lo que va a constituir la experiencia de Europa del Este, Asia y África durante los próximos ciento cincuenta años [...] hincando su carrera de independencia, como las repúblicas latinoamericanas iniciaron la suya, con poca experiencia política previa y sin una suficiente clase media. Por esto temo que por mucho tiempo, una mayoría de los actuales ciento veinticinco estados soberanos sobre la faz de este planeta va a vivir bajo regímenes que serán fanáticamente nacionalistas, pero no serán democráticos ni constitucionales (TOYNBEE 1966, p. 135).

Emerge aquí, nuevamente, un tópico que recorre buena parte de los discursos e intervenciones producidas en los tres congresos, el rol central de los historiadores para pensar e intervenir en las circunstancias presentes y para realizar una operación prospectiva a partir del conocimiento que les otorgaba su saber profesional. Desplegada en varias direcciones, esa embajada historiográfica y cultural se capilarizaría para la sociedad por medio de distintos dispositivos e instituciones relacionadas con la construcción de la cultura histórica. ${ }^{15}$ En ese sentido, las propuestas consensuadas en las sesiones plenarias finales de las distintas ediciones incluían recomendaciones heterogéneas como las de fortalecer la enseñanza de la historia y la geografía aumentando su carga horaria en el nivel medio y con una mayor presencia de la historia de América independiente; operar cambios en la formación docente; crear cátedras de Historia de la Civilización Española, Portuguesa e Inglesa; erigir monumentos en homenaje a próceres de las gestas americanas; emplear medios televisivos y films cortos para difundir sus vidas y los valores que sostuvieron.

\section{Algunas consideraciones finales}

Los congresos científicos considerados como objeto de estudio pueden abrir interesantes y novedosas perspectivas de análisis. Los congresos de historia en particular, tal como
15 - Seguimos el sentido de "cultura histórica" establecido por J. Rüsen: "La 'cultura histórica' contempla las diferentes estrategias de la investigación científico-académica, de la creación artística, de la lucha política por el poder, de la educación escolar y extraescolar, del ocio y de otros procedimientos de memoria histórica pública, como concreciones y expresiones de una única potencia mental" (RÜSEN 2009). 
fue argumentado, se destacan por su potencial aporte al ámbito de los análisis historiográficos, tanto de aquellos centrados en la historiografía profesional como de los que atienden a los vínculos entre el mundo académico y otros ámbitos. El caso aquí estudiado demuestra cómo en diferentes oportunidades esos eventos trascendieron los marcos del mundo académico y la estricta función científica para impactar en la política nacional o en la diplomacia internacional.

Los Congresos Internacionales de Historia de América llevados a cabo en Buenos Aires entre los años 1937 y 1966 ponen en evidencia la contribución de algunos historiadores - centralmente la de aquellos vinculados a la ANH y sus redes de sociabilidad - al diseño de una diplomacia cultural no menos eficaz que aquella a secas. La legitimidad de esa intervención devenía de la especificidad del saber detentado por los historiadores y de su capacidad para llevar adelante un estudio riguroso y objetivo del pasado. Esta operación erudita y crítica permitía sancionar determinados presentes como una consecuencia ineluctable de aquel pasado y, por lo tanto, proveerles legitimidad. Al mismo tiempo, le confería a la historia una capacidad prospectiva que hacía de ella una herramienta para reflexionar sobre posibles modos de reorientar procesos históricos abiertos.

Esta embajada historiográfica promovió la idea de una unidad histórica americana gestada en el pasado durante los siglos coloniales y consolidada a lo largo de la emancipación y los desarrollos nacionales posteriores. Brindaba así una fundamentación histórica que fue capitalizada y difundida en ámbitos extrahistoriográficos, pues esa unidad invocada permitía presentar en cada coyuntura ciertos proyectos y alineamientos políticos como una deriva natural de los procesos históricos. 


\section{REFERÊNCIAS BIBLIOGRÁFICAS}

BERGEL, Martin. El anti-antinorteamericanismo en América Latina (1898-1930). Apuntes para una historia intelectual.

Revista Nueva Sociedad, n. 236, nov-dic. 2011.

BLÄNSDORF, Agnes. Une collaboration scientifique "dans un esprit vraiment œcuménique et international": Les congrès internationaux d'historiens et le Comité International des Sciences Historiques dans l'Entre-deux-guerres. Revue Germanique Internationale, n. 12, p. 209-228, 2010.

CALMON, Pedro. Discurso del delegado del Brasil, invitado de honor. In: Academia Nacional de la Historia. II Congreso Internacional de Historia de América, Buenos Aires: Academia Nacional de la Historia, 1938. (T. I)

CATARUZZA, Alejandro; EUJANIAN Alejandro. Políticas de la Historia. Argentina 1860-1960. Buenos Aires: Alianza, 2003.

DEL ARENAL, Celestino. Política exterior de España hacia Iberoamérica. Madrid: Ed. Complutense, 1994, Cap. II.

DEVOTO, Fernando; PAGANO, Nora. Historia de la Historiografía Argentina. Buenos Aires: Sudamericana, 2009.

ERDMANNT, Karl. Toward a Global Community of Historians: The International Historical Congresses and the International Committee of Historical Sciences, 18982000. Edited by Jürgen Kocka and Wolfgang J. Mommsen in collaboration with Agnes Blänsdorf . New York: Berghahn Books, 2005

FEUERHAHN, Wolf; RABAULT-FEUERHAHN, Pascale. Présentation: la science à l'échelle internationale. Revue Germanique Internationale, n. 12, p. 5-15, 2010.

FITTE, Ernesto. Sesión Preparatoria. Informe presentado por el Presidente de la Comisión Organizadora y Secretario de la 
Academia Nacional de la Historia. In: Academia Nacional de la Historia Cuarto Congreso Internacional de Historia de América. Buenos Aires: Academia Nacional de la Historia, 1966. (T. I)

GINGRAS, Yves. Les formes spécifiques de l'internationalité du champ scientifique. Actes de la Recherche en Sciences Sociales, v. 141-142, p. 31-45, 2002.

HARING, Clarence. Discurso del delegado de Estados Unidos, invitado de honor. Academia Nacional de la Historia, II Congreso Internacional de Historia de América, Buenos Aires: Academia Nacional de la Historia. 1938. (T. I)

HÜBINGER, Gangolf; PICHT, Barbara; DABROWSKA, Ewa. Cultures historiques et politique scientifique. Les congrès internationaux des historiens avant la Première Guerre mondiale. Revue germanique internationale, n. 12, p. 175-191, 2010.

HUERTA, Mona. Breve retrospectiva del medio siglo del Instituto de los Altos Estudios de América Latina de París. Revista del CESLA, n. 7, p. 413-423, 2005.

LAURIERE, Christine. La discipline s'acquiert en s'internationalisant. L'exemple des congrès internationaux des américanistes (1875-1947). Revue Germanique Internationale, n. 12, p. 69-90, 2010.

LEVENE, Ricardo. Discurso del Presidente del Congreso y de la Junta de Historia y Numismática Americana. Academia Nacional de la Historia. II Congreso Internacional de Historia de América. Buenos Aires: Academia Nacional de la Historia, 1938. (T. I)

. La Cultura Histórica. Buenos Aires: EspasaCalpe, 1942.

LÓPEZ-OCÓN, Leoncio. El papel de los primeros congresos internacionales de americanistas en la construcción de una 
comunidad científica. In: BUSTAMANTE GARCÍA, Jesús; QUIJADA MOURIÑO, Mónica. Elites intelectuales y modelos colectivos. Mundo Ibérico (Siglos XVI-XIX). Madrid: CSIC, 2002, p. 271-284.

NINCOVICH, Frank. The Diplomacy of Ideas: U.S. Foreign Policy and Cultural Relations, 1938-1950. Cambridge: Cambridge University Press, 1981.

ORTEMBERG, Pablo. Los centenarios patrios en la construcción de alianzas y rivalidades internacionales: los festejos trasandinos de 1910, la estatua de O'Higgins y los bemoles peruanos. Anuario de Historia de América Latina, n. 51, p. 329-350, 2014.

PASCHOAL GUIMARÃES, Lúcia. Limites políticos de um projeto intelectual para a integração dos povos do Novo Mundo: o Primeiro Congresso Internacional de História da América (1922). Topoi, n. 10, p. 192-212, jan.-jun. 2005.

PEREZ HERRERO, Pedro; TABANERA, Nuria (Coords.). España/América Latina: un siglo de políticas culturales. Madrid: AIETI/OEI, 1993.

PERNET, Corinne. La cultura como política. Los intercambios culturales entre Europa y América Latina en los años de entreguerras. Puente@Europa. Noticias de Europa, noticias de América Latina, año V, n. 3-4, 2007.

PITA GONZALEZ, Alexandra. Panamericanismo y Nación. La perspectiva de Samuel G. Inman. Anuario IEHS, n. 32, 2017.

; MARICHAL, Carlos (coords). Pensar el antiimperialismo. Ensayos de historia intelectual latinoamericana, 1900-1930. México: El Colegio de México/ Universidad de Colima, 2012.

PRADO, Gustavo. Las lecciones historiográficas de Rafael Altamira en Argentina Apuntes sobre Ciencia, Universidad y Pedagogía Patriótica (1909). Asturias: 
Universidad de Oviedo, 2010.

PROCHASSON, Christophe. Les Congrès: lieux de l'échange intellectuel. Introduction. Mil neuf cent, n. 7, p. 5-8, 1989.

RODRIGUEZ, Martha. Los historiadores, las conmemoraciones y su celebración. El IV Congreso Internacional de Historia de América y el Sesquicentenario de la independencia. Jornadas. 200 años. Independencias, guerra y nuevos órdenes en América. Los tiempos convulsionados, las ideas y sus resonancias. Buenos Aires: Facultad de Ciencias SocialesUBA, 2016. (Mimeo)

Conmemoraciones, historiografía y mundo académico. El III Congreso Internacional de Historia de América. In: PAGANO, Nora (comp.). Patrimonio histórico, conmemoraciones y usos públicos del pasado argentino. Buenos Aires: Mnemosyne, 2017.

- Una embajada historiográfica con vocación americanista. Los historiadores argentinos en el II Congreso Internacional de Historia de América. Ariadna Tucma Revista Latinoamericana, n. 11/12, 2018.

RONZE, Raymond. Discurso del delegado de Francia y Académico Correspondiente. Academia Nacional de la Historia. III Congreso Internacional de Historia de América. Buenos Aires: Academia Nacional de la Historia. 1961. (T. I)

RÜSEN, Jörn. ¿Qué es la cultura histórica?: Reflexiones sobre una nueva manera de abordar la historia. Traducción de F. Sánchez Costa e Ib Schumacher. En: Cultura histórica, 2009. (Original en: FÜSSMANN, K.; GRÜTTER, H.T.; RÜSEN, J. [eds.] Historische Faszination: Geschichtskulturheute. Böhlau, 1984.)

SCARFI, Juan Pablo; PREUSS, Ori (eds.) Relaciones internacionales, identidades colectivas y vida intelectual en América Latina (1810-1945). Revista Complutense de 
Historia de América, n. 39, 2013.

TERAN, Oscar. Historia de la ideas en la Argentina. Diez lecciones iniciales 1810-1980. Buenos Aires: S. XXI, 2008.

TOYNBEE, Arnold. Primera Sesión Plenaria. Conferencia del delegado de la Gran Bretaña. Academia Nacional de la Historia. Cuarto Congreso Internacional de Historia de América. Buenos Aires: Academia Nacional de la Historia, 1966. (T. I)

UNESCO. La réforme des manuels scolaires et du matériel d'enseignement. Paris: Unesco, 1950.

ZORROAQUÍN BECÚ, Ricardo. Informe presentado por el secretario de la Comisión Organizadora y Vicepresidente 10 de la Academia Nacional de la Historia al Tercer Congreso Internacional de Historia de América. Academia Nacional de la Historia. III Congreso Internacional de Historia de América. Buenos Aires: Academia Nacional de la Historia, 1961. (T. I)

\section{AGRADECIMENTOS E INFORMAÇŌES}

\section{Martha Rodriguez}

mrod@fibertel.com.ar

Programa de Investigaciones en Historiografía Argentina (PIHA)

Instituto Ravignani (UBA/C ONICET)

Versiones preliminares de algunos apartados de este trabajo fueron presentadas en el IV Congreso Internacional de Filosofía de la Historia y en el workshop "Diplomáticos e intelectuales americanos en la construcción de las relaciones internacionales en el continente, 1880-1930" durante el año 2017. Agradezco los comentarios recibidos de los colegas que participaron en cada una de esas actividades. 